\title{
Evaluation of Scintillation and Thermally Stimulated Luminescence Properties of $\mathrm{Cs}_{2} \mathrm{CdCl}_{4}$ Single Crystals
}

\author{
Takumi Sakai, ${ }^{1}$ Masanori Koshimizu, ${ }^{1 *}$ Yutaka Fujimoto, ${ }^{1}$ \\ Daisuke Nakauchi, ${ }^{2}$ Takayuki Yanagida, ${ }^{2}$ and Keisuke Asai ${ }^{1}$ \\ ${ }^{1}$ Department of Applied Chemistry, Graduate School of Engineering, Tohoku University, \\ Sendai 980-8579, Japan \\ ${ }^{2}$ Graduate School of Materials Science, Nara Institute of Science and Technology, \\ Ikoma, Nara 630-0192, Japan
}

(Received January 5, 2018; accepted March 27, 2018)

Keywords: thermally stimulated luminescence, $\mathrm{s}-\mathrm{p}$ transition, $\mathrm{Cs}_{2} \mathrm{CdCl}_{4}$

The optical and scintillation properties of undoped, Sb-doped, and Tl-doped $\mathrm{Cs}_{2} \mathrm{CdCl}_{4}$ single crystals were investigated. We chose $\mathrm{Sb}^{3+}$ and $\mathrm{Tl}^{+}$as the dopants of (ns) ${ }^{2}$-type electronic configurations. In the photoluminescence and scintillation spectra of undoped $\mathrm{Cs}_{2} \mathrm{CdCl}_{4}$, three emission peaks were observed. The scintillation decay-time constants were small (1.2 and 13 $\mathrm{ns}$ ) and light yields were low (several tens of photons/MeV). In contrast, $\mathrm{Sb}^{3+}$ - and $\mathrm{Tl}^{+}$-doped $\mathrm{Cs}_{2} \mathrm{CdCl}_{4}$ showed $\mathrm{s}-\mathrm{p}$ transitions of the dopant ions, and the light yield was larger than that of undoped $\mathrm{Cs}_{2} \mathrm{CdCl}_{4}$ (625 and 1000 photons/ $\mathrm{MeV}$, respectively). Tl-doped $\mathrm{Cs}_{2} \mathrm{CdCl}_{4}$ showed relatively large scintillation decay-time constants $(270 \mathrm{~ns})$ because of slow energy transfer from the host to $\mathrm{Tl}^{+}$. On the other hand, $\mathrm{Sb}$-doped $\mathrm{Cs}_{2} \mathrm{CdCl}_{4}$ showed significant afterglow behavior and three thermally stimulated luminescence (TSL) glow peaks $\left(93,168\right.$, and $238^{\circ} \mathrm{C}$ ) with good linearity with respect to the $\mathrm{X}$-ray dose. In conclusion, the light yield of undoped $\mathrm{Cs}_{2} \mathrm{CdCl}_{4}$ can be enhanced by doping with $\mathrm{Sb}^{3+}$ and $\mathrm{Tl}^{+}$; TSL characteristics are achieved by doping $\mathrm{Sb}^{3+}$.

\section{Introduction}

In general, luminescent materials, such as those utilized in radiation detectors, show either of two types of luminescence behavior: immediate luminescence upon irradiation and luminescence upon external stimulation after irradiation. Luminescent materials exhibiting such behavior can be used as scintillators and dosimeters, respectively. Dosimeters store ionizing radiation energy as trapped electrons and holes and exhibit luminescence upon external stimulation by light (optically stimulated luminescence, OSL) or heat (thermally stimulated luminescence, TSL). They are mainly used for personal dose monitoring, and should exhibit suitable sensitivity, linear response to dose, and low fading. On the other hand, scintillators convert the absorbed energy of ionizing radiation immediately into low-energy photons. Scintillation detectors are composed of scintillation materials and a photomultiplier tube (PMT), avalanche photodiode, or Si-PMT, and play important roles in medical imaging, ${ }^{(1)}$ underground resources exploration, ${ }^{(2)}$ and security inspections. ${ }^{(3)}$

*Corresponding author: e-mail: koshi@qpc.che.tohoku.ac.jp http://dx.doi.org/10.18494/SAM.2018.1920 
Alkali metal halides are promising scintillation materials for the detection of high-energy photons such as X-rays or gamma rays because of their efficient light yields, high energy resolution, optical transparency, and low manufacturing costs, all of which make them favorable for many practical applications. In fact, NaI:Tl and CsI:Tl exhibit high light yields ( $\sim 40000$ and $\sim 50000$ photons $/ \mathrm{MeV}$, respectively) ${ }^{(4)}$ originating from $6 \mathrm{sp} \rightarrow 6 \mathrm{~s}^{2}$ transitions of $\mathrm{Tl}^{+}$ions, and they have been applied to X-ray and gamma ray detections for many years. However, both types of material have certain disadvantages as scintillators. For instance, NaI:Tl exhibits high hygroscopy in ambient atmosphere, which limits its applications. Its manufacture requires controlled humidity and special handling. CsI:Tl is free from the high hygroscopy exhibited by NaI:Tl; it exhibits a long afterglow attributed to the thermal ionization of trapped electrons $\left(\mathrm{Tl}^{0}\right)$ followed by radiative recombination with trapped holes $\left[\mathrm{V}_{\mathrm{kA}}\left(\mathrm{Tl}^{+}\right)\right]^{(5)}$ and possesses large decay time constants $\left(\tau_{1}=600 \mathrm{~ns}\right.$ and $\left.\tau_{2}=3.4 \mu \mathrm{s}\right)$ under gamma ray excitation, ${ }^{(6)}$ which leads to pulse pile-up in high-count-rate applications. Although the afterglow can be suppressed by codoping with $\mathrm{Eu}^{2+}, \mathrm{Sm}^{2+}, \mathrm{Yb}^{2+}$, or $\mathrm{Bi}^{3+}{ }^{+7-10)}$ the drawbacks of slow decay components have not yet been completely resolved. Thus, new scintillators having minimal hygroscopy, high light yield, and small decay time constants are required.

$\mathrm{Cs}_{2} \mathrm{CdCl}_{4}$ is a transparent nonhygroscopic crystal. The $\mathrm{Cs}_{2} \mathrm{CdCl}_{4}$ crystal is tetragonal and crystallizes in a $\mathrm{K}_{2} \mathrm{NiF}_{4}$-type structure having the space group I4/mmm with $a=5.26 \AA$ and $c=16.88 \AA$, and two equivalent molecules per unit cell. ${ }^{(11)}$ The divalent metal ions $\left(\mathrm{Cd}^{2+}\right)$ are surrounded by a tetragonal-type octahedron, slightly compressed $[(\mathrm{Cd}-\mathrm{Cl}(1)=2.64 \AA$ and $\mathrm{Cd}-$ $\mathrm{Cl}(2)=2.51 \AA)$ ] along the fourfold axis, which coincides with the crystallographic c-axis. ${ }^{(12)}$ This condition gives rise to a ligand field of $\mathrm{D}_{4 \mathrm{~h}}$ symmetry on the divalent site. According to a previous paper, ${ }^{(12)} \mathrm{Mn}^{2+}$-doped $\mathrm{Cs}_{2} \mathrm{CdCl}_{4}$ crystals exhibit intense $3 \mathrm{~d}^{\mathrm{n}}-3 \mathrm{~d}^{\mathrm{n}}$ transitions of $\mathrm{Mn}^{2+}$; detailed spectrum analysis indicated that $\mathrm{Mn}^{2+}$ substitutes for $\mathrm{Cd}^{2+}$ in the site that occupies the center of the octahedron. This result indicates that $\mathrm{Mn}^{2+}$-doped $\mathrm{Cs}_{2} \mathrm{CdCl}_{4}$ may exhibit efficient scintillation. However, $3 \mathrm{~d}^{\mathrm{n}}-3 \mathrm{~d}^{\mathrm{n}}$ transitions are not appropriate for scintillator applications because of their very long lifetime $(\sim \mathrm{ms})$. Alternatively, $\mathrm{ns}^{2}$-type ions (e.g., $\mathrm{Tl}^{+}, \mathrm{Sb}^{3+}$ ) exhibit $\mathrm{s}-\mathrm{p}$ transitions in a crystal field with octahedral symmetry, such as $\mathrm{KCl}$ and $\mathrm{KI}{ }^{(13,14)}$ The s$\mathrm{p}$ transitions of $\mathrm{ns}^{2}$-type ions, especially for $\mathrm{Tl}^{+}$, are an attractive mechanism for scintillators because of their efficient light yield ${ }^{(1)}$ and fast decay under UV excitation $(\sim$ several tens of nanoseconds). ${ }^{(15)}$ In addition to $\mathrm{Tl}^{+}, \mathrm{Sb}^{3+}$ ions are another possible dopant owing to their similar electron configuration to that of $\mathrm{Tl}^{+}$. According to a previous paper, ${ }^{(16)} \mathrm{Sb}^{3+}$ can behave as a luminescence center in $\mathrm{Cs}_{2} \mathrm{Na} M \mathrm{Cl}_{6}(M=\mathrm{Sc}, \mathrm{Y}, \mathrm{La})$, the crystal structure of which has octahedral symmetry as in $\mathrm{Cs}_{2} \mathrm{CdCl}_{4}$. Thus, $\mathrm{Sb}^{3+}$ ions are expected to function as luminescence centers in $\mathrm{Cs}_{2} \mathrm{CdCl}_{4}$. On the other hand, it has been reported that $\mathrm{Sb}$-doped $\mathrm{Sr}_{2} \mathrm{SnO}_{4}$ shows TSL glow peaks due to the $\mathrm{s}-\mathrm{p}$ transitions of $\mathrm{Sb}^{3+}$ after irradiation with UV light. ${ }^{(17)}$ This indicates that $\mathrm{Sb}$-doped $\mathrm{Cs}_{2} \mathrm{CdCl}_{4}$ may behave as a dosimeter.

In this study, the photoluminescence (PL) and scintillation properties of undoped, Sb-doped, and Tl-doped $\mathrm{Cs}_{2} \mathrm{CdCl}_{4}$ crystals were investigated at room temperature using X-ray-excited luminescence spectra, pulse height spectra, and scintillation decay curves. The dosimeter properties of the $\mathrm{Sb}$-doped $\mathrm{Cs}_{2} \mathrm{CdCl}_{4}$ crystal were also investigated using TSL measurements. 


\section{Experimental Procedure}

Single crystals of undoped, Sb-doped, and Tl-doped $\mathrm{Cs}_{2} \mathrm{CdCl}_{4}$ were grown via the Bridgman-Stockbarger method. Prior to crystal growth, raw powders of $\mathrm{CsCl}$ (99.999\%, HighPurity Chemical, Japan), $\mathrm{CdCl}_{2}$ (99.9\%, High-Purity Chemical, Japan), and $\mathrm{SbCl}_{3}$ (99.999\%, Wako, Japan) or $\mathrm{TlCl}(99.999 \%$, Wako, Japan) were thoroughly mixed in a stoichiometric ratio and dried at $423 \mathrm{~K}$ for one day to remove water. The crystals were grown under vacuum in sealed quartz ampules. The molar concentrations of $\mathrm{Sb}$ or $\mathrm{Tl}$ in the melt were $0.1 \mathrm{~mol} \%$. Crystals larger than $1 \mathrm{~mm}$ were used for optical and scintillation characterizations. Powder $\mathrm{X}$-ray diffraction (XRD) measurements revealed that all the samples had the tetragonal $\mathrm{Cs}_{2} \mathrm{CdCl}_{4}$ structure.

PL measurements were carried out using a spectrofluorometer (Hitachi, Japan, F-7000) in air at room temperature. The PL spectra of undoped $\mathrm{Cs}_{2} \mathrm{CdCl}_{4}$ were measured using synchrotron radiation in the vacuum ultraviolet (VUV) region as the excitation source at BL7B at UVSOR, IMS, Japan. The X-ray-induced radioluminescence (RL) spectra were obtained using an X-ray tube operated at $80 \mathrm{kV}$ and $1.2 \mathrm{~mA}$ as the excitation source. The spectra were recorded using a Peltier-cooled charge-coupled device (CCD; Andor, US, DU-920-P) combined with a monochromator (Andor, US, SR163i-UV). ${ }^{(18)}$ The pulse height spectra of the samples were obtained using a photomultiplier tube (Hamamatsu, Japan, R7600U) under 662 $\mathrm{keV} \gamma$-ray irradiation from ${ }^{137} \mathrm{Cs} .{ }^{(19)}$ The scintillation temporal profiles were obtained via a time-correlated single-photon counting method with a pulsed X-ray excitation source. ${ }^{(20)}$ To investigate the dosimeter properties, we measured the TSL glow curve with an original setup consisting of a heater (SAT0983a, Sakaguchi, Japan), a thermostat (SCR-SHQ-A, Sakaguchi, Japan), and a photomultiplier tube (PMT; H11890-210, Hamamatsu, Japan). The heating rate for the TSL measurements was set to $0.5{ }^{\circ} \mathrm{C} / \mathrm{s}$, and the sample was heated from 36.5 to 290 ${ }^{\circ} \mathrm{C}$ to measure the glow curve. Furthermore, the TSL spectrum was measured using a CCDbased spectrometer (QE pro, Ocean Optics, US), while the sample was heated by an electric heater (SCR-SHQ-A, Sakaguchi, Japan, E. H. Voc) at a constant temperature. The sample was immediately heated to each temperature after irradiation.

\section{Results and Discussion}

\subsection{Samples}

Photographs of the undoped, Sb-doped, and Tl-doped $\mathrm{Cs}_{2} \mathrm{CdCl}_{4}$ crystals are shown in Fig. 1. The samples had cracks and were not hygroscopic.

\subsection{Photoluminescence properties}

The room-temperature PL spectra of an undoped $\mathrm{Cs}_{2} \mathrm{CdCl}_{4}$ crystal with excitations at 58 and $200 \mathrm{~nm}$ are shown in Fig. 2(a). Emission peaks at 320 and $600 \mathrm{~nm}$ are observed with excitations at 58 and $200 \mathrm{~nm}$, and an emission peak at $430 \mathrm{~nm}$ is observed only with excitation at $58 \mathrm{~nm}$. The origins of the emission bands at 320 and $430 \mathrm{~nm}$ are unclear at present; the possibilities are 


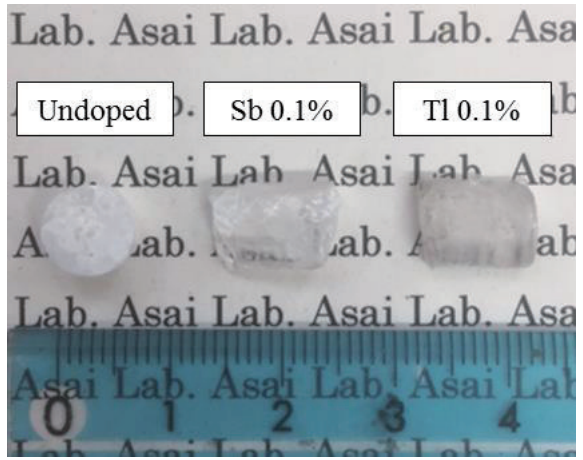

Fig. 1. (Color online) Photograph of undoped, Sb-doped, and Tl-doped $\mathrm{Cs}_{2} \mathrm{CdCl}_{4}$ crystals.

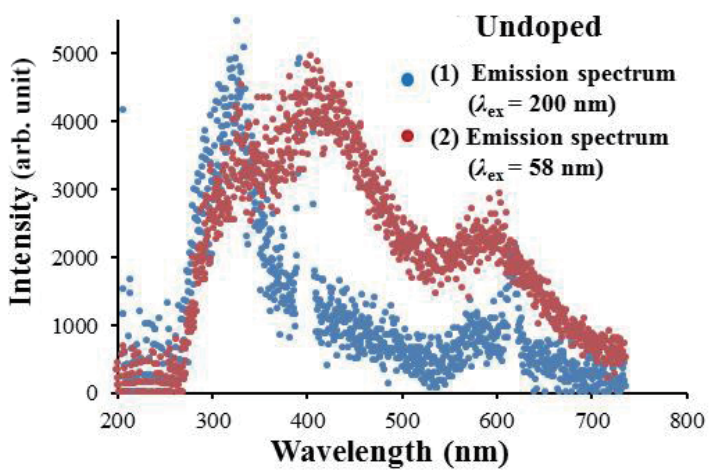

(a)

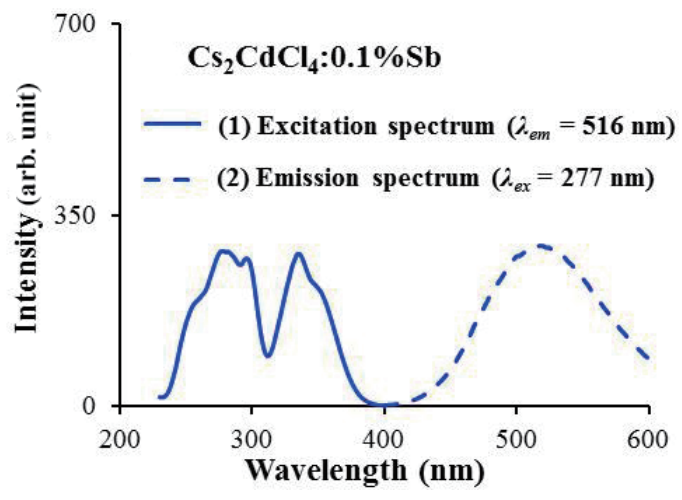

(b)

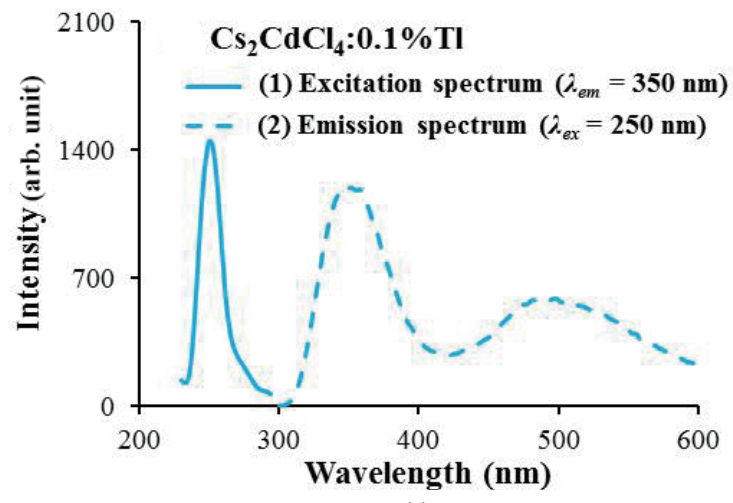

(c)

Fig. 2. (Color online) (a) VUV emission spectra of undoped $\mathrm{Cs}_{2} \mathrm{CdCl}_{4}$ crystal, and PL spectra (dotted lines) and PL excitation spectra (solid lines) of (b) Sb-doped and (c) Tl-doped $\mathrm{Cs}_{2} \mathrm{CdCl}_{4}$ crystals at room temperature. For undoped $\mathrm{Cs}_{2} \mathrm{CdCl}_{4}$, the excitation wavelengths are (1) $\lambda_{e x}=200 \mathrm{~nm}$ and (2) $\lambda_{e x}=58 \mathrm{~nm}$. For $\mathrm{Cs}_{2} \mathrm{CdCl}_{4}: 0.1 \% \mathrm{Sb}$, the excitation and emission wavelengths are (1) $\lambda_{e m}=516 \mathrm{~nm}$ and (2) $\lambda_{e x}=277 \mathrm{~nm}$. For $\mathrm{Cs}_{2} \mathrm{CdCl}_{4}: 0.1 \% \mathrm{Tl}$, the excitation and emission wavelengths are (1) $\lambda_{e m}=350 \mathrm{~nm}$ and (2) $\lambda_{e x}=250 \mathrm{~nm}$.

electronic transitions at defects, self-trapped excitons (STEs), and Auger-free luminescence (AFL). AFL is the radiative transition of an electron from the valence band to the uppermost core level, which can be observed only with excitation energies higher than the binding energy of the core level, e.g., $14 \mathrm{eV}$ for $\mathrm{CsCl}^{(21)}$ In the case of undoped $\mathrm{Cs}_{2} \mathrm{CdCl}_{4}$, the two emission peaks did not 
show a threshold-like behavior in the excitation energy. For this reason, AFL is excluded from consideration as the origin.

The excitation and PL spectra of Sb- and Tl-doped $\mathrm{Cs}_{2} \mathrm{CdCl}_{4}$ are shown in Figs. 2(b) and 2(c), respectively. In the case of the $\mathrm{Cs}_{2} \mathrm{CdCl}_{4}: \mathrm{Sb}$ crystal, the excitation spectrum recorded for $\lambda_{e m}=516 \mathrm{~nm}$ consists of five bands: a triplet at 254, 277, and $296 \mathrm{~nm}$, and a doublet at 336 and $350 \mathrm{~nm}$. According to previous studies, ${ }^{(13,16,22)}$ the triplet and doublet bands are ascribed to the ${ }^{1} \mathrm{~T}_{1 \mathrm{u}} \rightarrow{ }^{1} \mathrm{~A}_{1 \mathrm{~g}}$ and ${ }^{3} \mathrm{~T}_{1 \mathrm{u}} \rightarrow{ }^{1} \mathrm{~A}_{1 \mathrm{~g}}$ transitions of $\mathrm{Sb}^{3+}$, respectively. A similar splitting of excitation peaks has been observed for alkali metal halide crystals doped with $\mathrm{ns}^{2}$-type ions such as $\mathrm{Pb}^{2+},{ }^{23-25)} \mathrm{Tl}^{+},{ }^{(26)}$ and $\mathrm{Sn}^{2+(27-29)}$ and has been explained in terms of thermal lattice vibrations. ${ }^{(29,30)}$ The adiabatic potential energy surface (APES) of the excited state is split for general distorted lattice configurations, although it is degenerate in the equilibrium configuration of the ground state. Thus, thermal vibrations, i.e., the dynamical Jahn-Teler effect, cause instantaneous splitting of the excitation bands, ${ }^{(29,30)}$ and the observed splitting in the excitation bands in Fig. 2(b) is attributed to this phenomenon. In the emission spectrum recorded at $\lambda_{e x}=277 \mathrm{~nm}$, a broad peak at $516 \mathrm{~nm}$ is observed. According to a previous study of $\mathrm{Sb}^{3+}$-doped $\mathrm{Cs}_{2} \mathrm{Na} \mathrm{MCl}_{6}(M$ $=\mathrm{Sc}, \mathrm{La}, \mathrm{Y}),{ }^{(16)}$ this broad peak is attributed to the ${ }^{3} \mathrm{~T}_{1 \mathrm{u}} \rightarrow{ }^{1} \mathrm{~A}_{1 \mathrm{~g}}$ transition of $\mathrm{Sb}^{3+}$. In general, $\mathrm{ns}^{2}$-type ions doped into alkali metal halide crystals exhibit two types of emission peaks, the so-called $\mathrm{Ax}$ and $\mathrm{A}_{\mathrm{T}}$ emissions, which arise from two minima on the APES of the ${ }^{3} \mathrm{~T}_{1 \mathrm{u}}$ relaxed excited state. These minima are due to the Jahn-Teller coupling to the $\varepsilon_{g}$ and $\tau_{2 g}$ lattice modes. ${ }^{(15)}$ However, the shapes of these emission peaks excited at the other excitation wavelength (254, 296, 336, and $350 \mathrm{~nm}$ ) are almost the same. This result indicates that the Jahn-Teller interaction working on the ${ }^{3} \mathrm{~T}_{\mathrm{lu}}$ APES does not lead to two emissions (the $\mathrm{Ax}$ and $\mathrm{A}_{\mathrm{T}}$ emissions). $\mathrm{A}$ similar case was reported for Sb-doped elpasolite-type crystals such as $\mathrm{Cs}_{2} \mathrm{Na} \mathrm{CCl}_{6}(M=\mathrm{Sc}, \mathrm{Y}$, La). ${ }^{(16,31)}$ In $\mathrm{Cs}_{2} \mathrm{NaMCl}_{6}$, the $\mathrm{Sb}^{3+}$ ion substitutes at the $\mathrm{M}^{3+}$ ion site with octahedral symmetry. Considering that the PL properties of $\mathrm{Cs}_{2} \mathrm{Na}_{M} \mathrm{Cl}_{6}: \mathrm{Sb}^{3+}$ and $\mathrm{Cs}_{2} \mathrm{CdCl}_{4}: \mathrm{Sb}^{3+}$ are similar, the $\mathrm{Sb}^{3+}$ ion should substitute at the $\mathrm{Cd}^{2+}$ site, which occupies the center of octahedral symmetry as in $\left[\mathrm{SbCl}_{6}\right]^{3-}$.

In the emission spectrum of the $\mathrm{Cs}_{2} \mathrm{CdCl}_{4}: \mathrm{Tl}$ crystal recorded at $\lambda_{e x}=250 \mathrm{~nm}$, a narrow peak and a broad peak are observed at 350 and $490 \mathrm{~nm}$, respectively. Considering that the wavelengths of the emission peaks are similar to those of CsCl:Tl, ${ }^{(32-35)}$ the narrow peak $(350$ $\mathrm{nm})$ and the broad peak $(490 \mathrm{~nm})$ are ascribed to the ${ }^{3} \mathrm{P}_{1} \rightarrow{ }^{1} \mathrm{~S}_{0}$ transition of $\mathrm{Tl}^{+}$and off-center STEs, respectively. Accordingly, the excitation peak recorded at $\lambda_{e m}=350 \mathrm{~nm}$ is attributed to the ${ }^{1} \mathrm{~S}_{0} \rightarrow{ }^{3} \mathrm{P}_{1}$ transition of $\mathrm{Tl}^{+}$.

\subsection{Scintillation properties}

Figure 3 shows the X-ray-induced RL (XRL) spectra of the undoped, Sb-doped, and Tldoped $\mathrm{Cs}_{2} \mathrm{CdCl}_{4}$ crystals. In the case of undoped $\mathrm{Cs}_{2} \mathrm{CdCl}_{4}$, three narrow peaks at 320,360 , and $400 \mathrm{~nm}$, a weak band at $450 \mathrm{~nm}$, and a broad peak with a maximum intensity at $600 \mathrm{~nm}$ are observed. In the PL spectra with VUV excitation, the emission peaks at 320 and $360 \mathrm{~nm}$ may not be resolved. The emission peaks in the RL spectrum have the same origin as those in the PL spectra. 


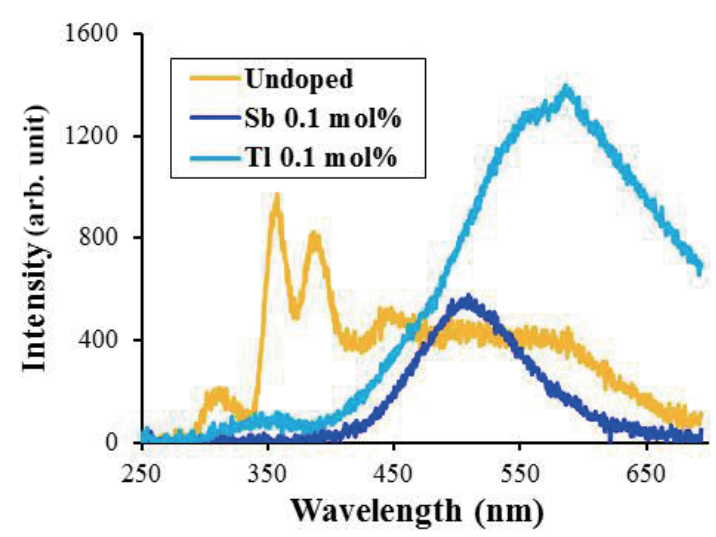

Fig. 3. (Color online) Room-temperature X-ray-excited luminescence spectra of undoped, Sb-doped, and Tldoped $\mathrm{Cs}_{2} \mathrm{CdCl}_{4}$ crystals. The lines show undoped $\mathrm{Cs}_{2} \mathrm{CdCl}_{4}$ (red-orange line), $\mathrm{Cs}_{2} \mathrm{CdCl}_{4}: 0.1 \% \mathrm{Sb}$ (blue line), and $\mathrm{Cs}_{2} \mathrm{CdCl}_{4}: 0.1 \% \mathrm{Tl}$ (light blue line).

In the spectrum of the $\mathrm{Cs}_{2} \mathrm{CdCl}_{4}: \mathrm{Sb}$ crystal, a broad peak at $520 \mathrm{~nm}$, which is ascribed to the ${ }^{3} \mathrm{~T}_{1 \mathrm{u}} \rightarrow{ }^{1} \mathrm{~A}_{\mathrm{lg}}$ transition of $\mathrm{Sb}^{3+}$, is observed. On the other hand, in the spectrum of the $\mathrm{Cs}_{2} \mathrm{CdCl}_{4}: \mathrm{Tl}$ crystal, in addition to the peak at $350 \mathrm{~nm}$, which is also seen in the PL spectrum, we observed a broad intense peak at $600 \mathrm{~nm}$, which is not seen in the PL spectra. This case is similar to that of CsI:Tl. In the PL spectra of CsI:Tl, ${ }^{(36)}$ there are four peaks; the two weak ones were ascribed to $\mathrm{Ax}(375 \mathrm{~nm})$ and $\mathrm{A}_{\mathrm{T}}(401 \mathrm{~nm})$ emissions of $\mathrm{Tl}^{+}$, while the other two intense peaks (486 and $550 \mathrm{~nm}$ ) were ascribed to off-center configurations of STEs perturbed by $\mathrm{Tl}^{+}$. In the XRL spectra of CsI:Tl, ${ }^{(5)}$ an intense broad peak at $550 \mathrm{~nm}$ was observed and attributed to the thermal ionization of trapped electrons $\left(\mathrm{Tl}^{0}\right)$ followed by their radiative recombination with trapped holes. Thus, as for $\mathrm{Cs}_{2} \mathrm{CdCl}_{4}$, a similar mechanism may result in the difference between the PL spectra and the XRL spectra.

The pulse height spectra of the undoped, Sb-doped, and Tl-doped $\mathrm{Cs}_{2} \mathrm{CdCl}_{4}$ crystals are shown in Fig. 4. To estimate the light yields of these crystals, a $\mathrm{Gd}_{2} \mathrm{SiO}_{5}$ :Ce (GSO) crystal, whose light yield is 10000 photons $/ \mathrm{MeV}$, was used for comparison. The peak at channel 630 corresponds to the full-energy peak of GSO. The course gain was 10 times larger for the undoped $\mathrm{Cs}_{2} \mathrm{CdCl}_{4}$ and 50 times larger for $\mathrm{Cs}_{2} \mathrm{CdCl}_{4}: \mathrm{Sb}_{\text {and }} \mathrm{Cs}_{2} \mathrm{CdCl}_{4}: \mathrm{Tl}$ than for GSO. The full-energy peaks of the undoped $\mathrm{Cs}_{2} \mathrm{CdCl}_{4}$ crystal were not clearly visible, so the light yield of undoped $\mathrm{Cs}_{2} \mathrm{CdCl}_{4}$ cannot be estimated. On the other hand, shoulders are observed at channels 250 and 180 in the pulse height spectra of the $\mathrm{Cs}_{2} \mathrm{CdCl}_{4}: \mathrm{Sb}_{\text {and }} \mathrm{Cs}_{2} \mathrm{CdCl}_{4}: \mathrm{Tl}$ crystals, respectively, although they are not well resolved. Assuming that these shoulders correspond to the full-energy peaks, and considering the quantum efficiencies of the bialkali photocathode of the PMT for GSO (28\% for $430 \mathrm{~nm}), \mathrm{Cs}_{2} \mathrm{CdCl}_{4}: \mathrm{Sb}(10 \%$ for $520 \mathrm{~nm})$, and $\mathrm{Cs}_{2} \mathrm{CdCl}_{4}: \mathrm{Tl}(2.5 \%$ for $600 \mathrm{~nm}$ ), the light yields of $\mathrm{Cs}_{2} \mathrm{CdCl}_{4}: \mathrm{Sb}$ and $\mathrm{Cs}_{2} \mathrm{CdCl}_{4}: \mathrm{Tl}$ crystals are estimated to be 600 and 1000 photons $/ \mathrm{MeV}$, respectively.

The scintillation temporal profiles of the undoped, Sb-doped, and Tl-doped $\mathrm{Cs}_{2} \mathrm{CdCl}_{4}$ crystals are shown in Fig 5. The scintillation decay-time constants were deduced from the sums of two or three exponential decay functions. Table 1 summarizes the decay-time constants and relative intensities. The decay-time constants for the undoped $\mathrm{Cs}_{2} \mathrm{CdCl}_{4}$ crystal are 1.2 and 


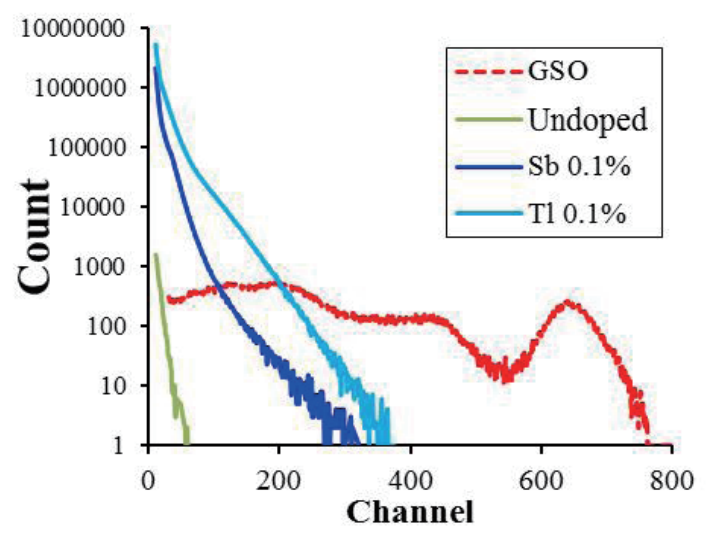

Fig. 4. (Color online) Pulse-height spectra of undoped, Sb-doped, and Tl-doped $\mathrm{Cs}_{2} \mathrm{CdCl}_{4}$ crystals. The lines show GSO (dotted red line), undoped $\mathrm{Cs}_{2} \mathrm{CdCl}_{4}$ (light green line), $\mathrm{Cs}_{2} \mathrm{CdCl}_{4}: 0.1 \% \mathrm{Sb}$ (blue line), and $\mathrm{Cs}_{2} \mathrm{CdCl}_{4}: 0.1 \% \mathrm{Tl}$ (light blue line).

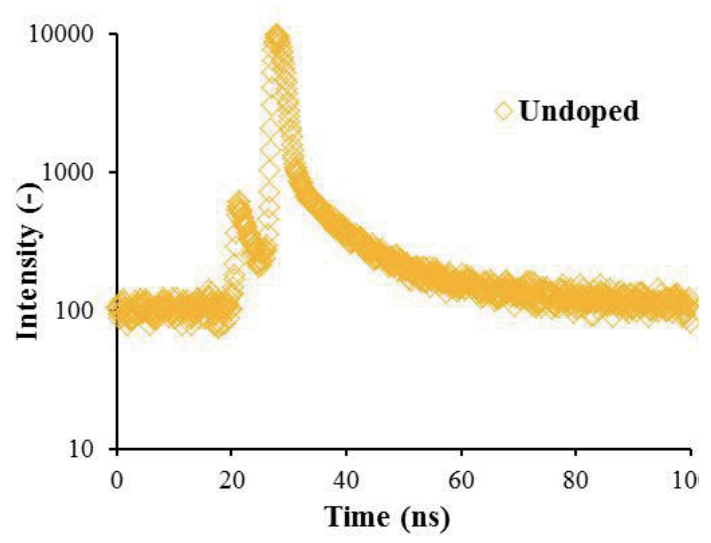

(a)

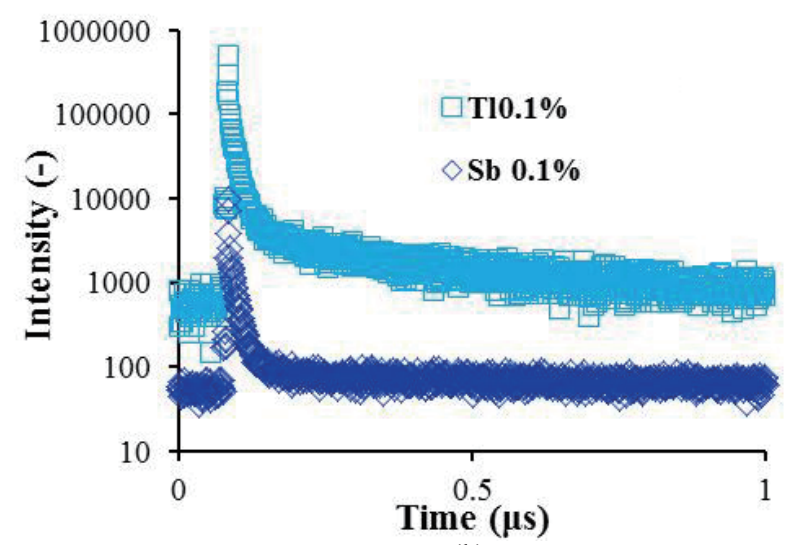

(b)

Fig. 5. (Color online) Scintillation temporal profiles of (a) an undoped $\mathrm{Cs}_{2} \mathrm{CdCl}_{4}$ crystal and (b) Sb-doped and Tldoped $\mathrm{Cs}_{2} \mathrm{CdCl}_{4}$ crystals.

Table 1

Decay-time constants and relative intensities of scintillation temporal profiles of undoped, Sb-doped, and Tldoped $\mathrm{Cs}_{2} \mathrm{CdCl}_{4}$ crystals. The words "fast", "middle", and "slow" in this table refer to "fast components", "middle components", and "slow components" of the crystal, respectively.

\begin{tabular}{|c|c|c|c|c|c|c|c|}
\hline & \multicolumn{2}{|c|}{ Undoped } & \multicolumn{3}{|c|}{ Sb-doped } & \multicolumn{2}{|c|}{ Tl-doped } \\
\hline & fast & slow & fast & middle & slow & fast & slow \\
\hline Decay-time constant $\tau$ (ns) & 1.2 & 13 & 0.8 & 11 & 270 & 6 & 200 \\
\hline Relative intensity (\%) & 66 & 34 & 28 & 53 & 18 & 63 & 37 \\
\hline
\end{tabular}

13 ns. On the other hand, the decay-time constants for the Sb-doped or Tl-doped $\mathrm{Cs}_{2} \mathrm{CdCl}_{4}$ crystals are composed of a fast component due to host luminescence ( 0.8 and $11 \mathrm{~ns}$ for the Sbdoped sample and $6 \mathrm{~ns}$ for the Tl-doped sample) and slow components due to each dopant ion (270 $\mathrm{ns}$ for the Sb-doped sample and $200 \mathrm{~ns}$ for the Tl-doped sample). According to the intensity ratio, the emissions due to the $s-p$ transitions of the dopant ions do not contribute significantly to the scintillation. 


\subsection{Dosimeter properties}

To investigate the origin of the afterglow of $\mathrm{Cs}_{2} \mathrm{CdCl}_{4}: \mathrm{Sb}$, TSL glow curves after irradiation with X-rays at doses of 1, 10, and $100 \mathrm{~Gy}$ are shown in Fig. 6. The $\mathrm{Cs}_{2} \mathrm{CdCl}_{4}$ :Sb crystal shows glow peaks near 91,166 , and $242{ }^{\circ} \mathrm{C}$. The activation energies are derived using the initial rise method $^{(37)}$ on the assumption of first-order kinetics. The intensities at the glow peaks increased proportionally with dose with a negligible change in the glow curve. Therefore, it is appropriate to consider the TSL process as first-order, although first-order kinetics have not been confirmed in this study. ${ }^{(38)}$ The peaks at higher temperatures were analyzed without eliminating the peak at lower temperature because the glow peaks were well separated in temperature. The estimated values are summarized in Table 2. Figure 7 shows the TSL spectra near the glow peaks $\left(93,168\right.$, and $\left.238^{\circ} \mathrm{C}\right)$. The TSL spectra show the same peak with a maximum intensity near $520 \mathrm{~nm}$, which is attributed to the ${ }^{3} \mathrm{~T}_{1 \mathrm{u}} \rightarrow{ }^{1} \mathrm{~A}_{1 \mathrm{~g}}$ transition of $\mathrm{Sb}^{3+}$. Thus, it is implied that the afterglow also resulted from the ${ }^{3} \mathrm{~T}_{1 \mathrm{u}} \rightarrow{ }^{1} \mathrm{~A}_{1 \mathrm{~g}}$ transition of $\mathrm{Sb}^{3+}$. Figure 8 shows the relationship between the TSL intensity and X-ray dose, namely, the dose response curve. The dose response curves for all the glow peaks have good linearity. This result indicates that the Sb-doped $\mathrm{Cs}_{2} \mathrm{CdCl}_{4}$ may be used for dosimetry. In addition, the significant TSL may be a reason for the small light yield of Sb-doped $\mathrm{Cs}_{2} \mathrm{CdCl}_{4}$. Figure 9 shows the TSL glow curves of the undoped $\mathrm{Cs}_{2} \mathrm{CdCl}_{4}$ crystal after X-ray irradiation from 1 to $100 \mathrm{~Gy}$. A dominant peak is observed at $93{ }^{\circ} \mathrm{C}$ with a small shoulder at $170{ }^{\circ} \mathrm{C}$. From the comparison of the glow curves of undoped and $\mathrm{Sb}$-doped $\mathrm{Cs}_{2} \mathrm{CdCl}_{4}$, the glow peaks at 93 and $168{ }^{\circ} \mathrm{C}$ for $\mathrm{Sb}$-doped $\mathrm{Cs}_{2} \mathrm{CdCl}_{4}$ are attributed to the trapping sites in the $\mathrm{Cs}_{2} \mathrm{CdCl}_{4}$ host; on the other hand, the glow peak at $238^{\circ} \mathrm{C}$ is attributed to $\mathrm{Sb}^{3+}$-related centers.

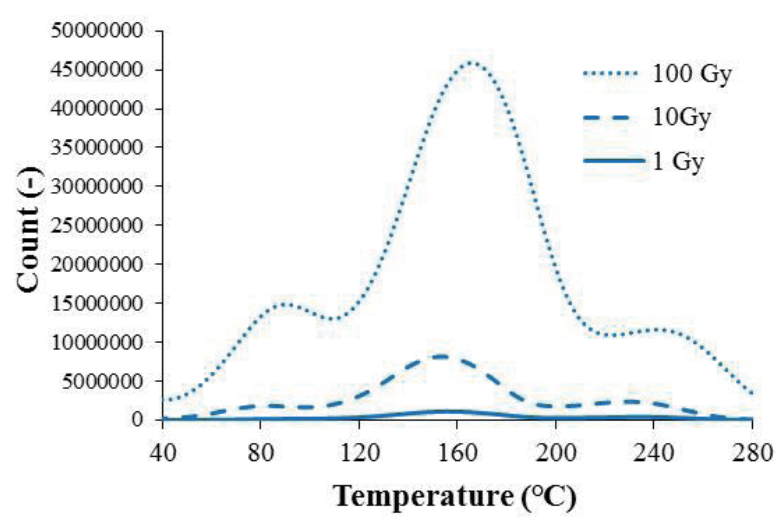

Fig. 6. (Color online) TSL glow curves of a $\mathrm{Cs}_{2} \mathrm{CdCl}_{4}: 0.1 \% \mathrm{Sb}$ crystal after X-ray irradiation from 1 to $100 \mathrm{~Gy}$.

Table 2

Glow peak temperature and estimated activation energies of a $\mathrm{Cs}_{2} \mathrm{CdCl}_{4}: 0.1 \% \mathrm{Sb}$ crystal.

\begin{tabular}{lcc}
\hline Sample & Peak temperature $\left({ }^{\circ} \mathrm{C}\right)$ & Activation energy $(\mathrm{eV})$ \\
\hline & 90.5 & 0.22 \\
$\mathrm{Cs}_{2} \mathrm{CdCl}_{4}: 0.1 \% \mathrm{Sb}$ & 165.5 & 0.51 \\
& 242 & 0.64 \\
\hline
\end{tabular}




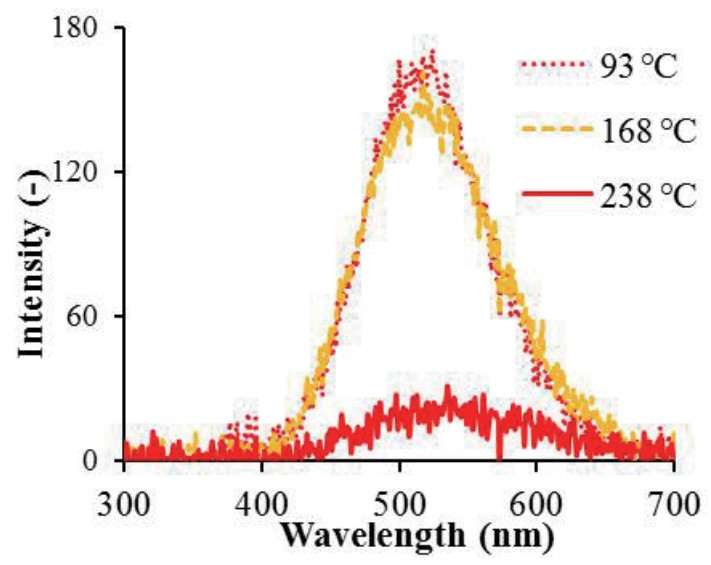

Fig. 7. (Color online) TSL spectra of a $\mathrm{Cs}_{2} \mathrm{CdCl}_{4}: 0.1 \% \mathrm{Sb}$ crystal measured at 93 (red dotted line), 168 (red-orange dotted line), and $238{ }^{\circ} \mathrm{C}$ (red solid line). The inset expands the $300-700 \mathrm{~nm}$ regions.

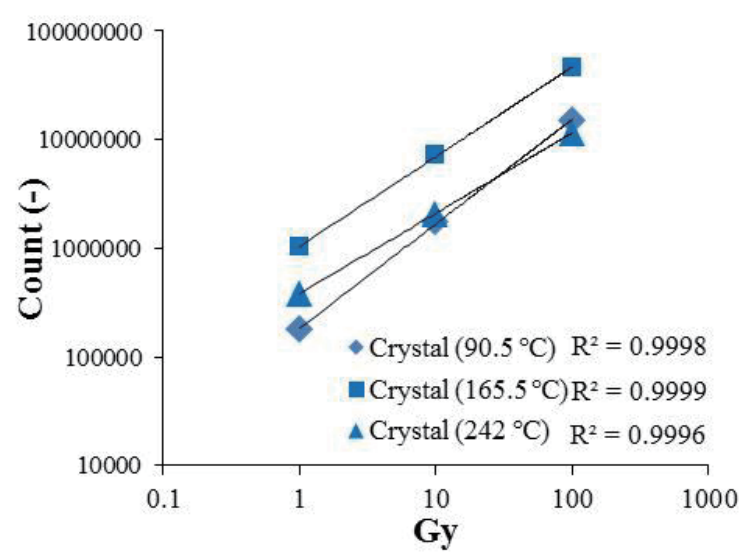

Fig. 8. (Color online) Dose response curve of $\mathrm{Cs}_{2} \mathrm{CdCl}_{4}: 0.1 \% \mathrm{Sb}$ crystal. The TSL signals used here are the peak intensities observed at 90.5 (diamonds), 165.5 (squares), and $242{ }^{\circ} \mathrm{C}$ (triangules).

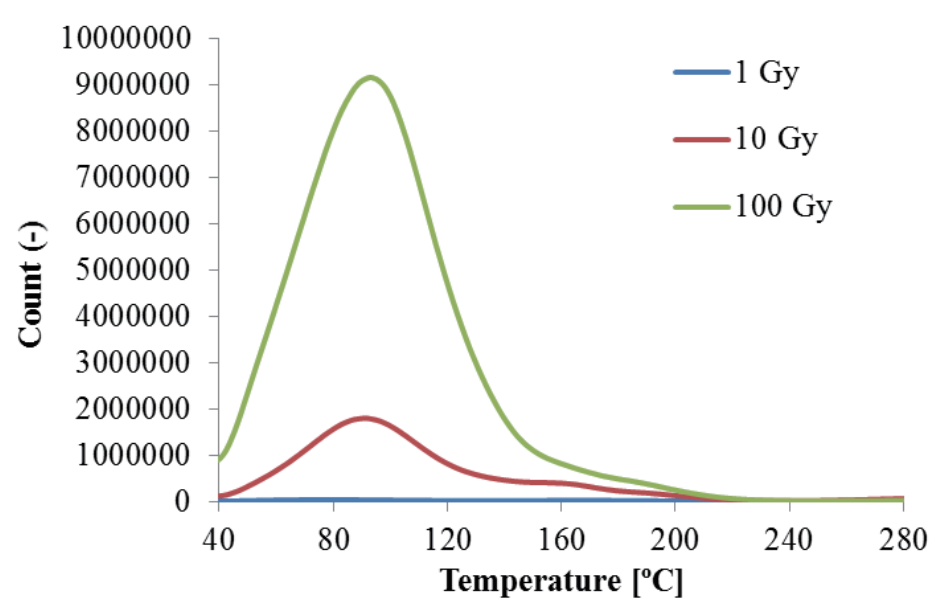

Fig. 9. (Color online) TSL glow curves of an undoped $\mathrm{Cs}_{2} \mathrm{CdCl}_{4}$ crystal after X-ray irradiation from 1 to $100 \mathrm{~Gy}$.

\section{Conclusion}

Undoped, Tl-doped, and $\mathrm{Sb}$-doped $\mathrm{Cs}_{2} \mathrm{CdCl}_{4}$ crystals were synthesized using the BridgmanStockbarger method, and their optical, scintillation, and dosimeter properties were evaluated. In the room-temperature PL spectra, the undoped $\mathrm{Cs}_{2} \mathrm{CdCl}_{4}$ crystal exhibited three types of emission peaks, and the AFL was excluded as the origin of the emission. In the case of a Sbdoped $\mathrm{Cs}_{2} \mathrm{CdCl}_{4}$ crystal, the splitting of excitation bands due to the dynamical Jahn-Teller effect and the $\mathrm{A}_{x}$ emission of $\mathrm{Sb}^{3+}$ were observed. These results are similar to those in the case of Sb-doped $\mathrm{Cs}_{2} \mathrm{NaMCl}_{6}(M=\mathrm{Sc}, \mathrm{La}, \mathrm{Y})$ and indicate that $\mathrm{Sb}^{3+}$ ions substitute for the $\mathrm{Cd}^{2+}$ site, which occupies the center in octahedral symmetry. For the Tl-doped $\mathrm{Cs}_{2} \mathrm{CdCl}_{4}$ crystal, emissions due to ${ }^{3} \mathrm{P}_{1} \rightarrow{ }^{1} \mathrm{~S}_{0}$ transitions of $\mathrm{Tl}^{+}$and off-center STEs were observed. Under X-ray 
irradiation, the undoped and $\mathrm{Sb}$-doped $\mathrm{Cs}_{2} \mathrm{CdCl}_{4}$ crystals showed emission peaks similar to those in the PL spectra. On the other hand, the Tl-doped $\mathrm{Cs}_{2} \mathrm{CdCl}_{4}$ crystal exhibited an additional emission peak, which is attributed to off-center configurations of STEs perturbed by $\mathrm{Tl}^{+}$or the thermal ionization of trapped electrons $\left(\mathrm{Tl}_{0}\right)$ followed by radiative recombination with trapped holes. According to the pulse height spectra, the light yields of undoped $\mathrm{Cs}_{2} \mathrm{CdCl}_{4}$ were slightly enhanced by doping with $\mathrm{Sb}^{3+}$ and $\mathrm{Tl}^{+}$(625 and 1000 photons/MeV, respectively). The scintillation decay-time constants for the undoped $\mathrm{Cs}_{2} \mathrm{CdCl}_{4}$ crystal were small (1.2 and $13 \mathrm{~ns}$ ). The $\mathrm{Sb}$ - or Tl-doped $\mathrm{Cs}_{2} \mathrm{CdCl}_{4}$ crystals exhibited, in addition to the fast component due to host luminescence, slow components due to the dopant ions as a relatively small contribution (270 ns and $18 \%$ for the Sb-doped sample, and $200 \mathrm{~ns}$ and $37 \%$ for the Tl-doped sample). Furthermore, significant afterglow was observed for the $\mathrm{Cs}_{2} \mathrm{CdCl}_{4}: \mathrm{Sb}$ crystal. The TSL glow curves of $\mathrm{Cs}_{2} \mathrm{CdCl}_{4}: \mathrm{Sb}$ are composed of three glow peaks at 91,166 , and $242{ }^{\circ} \mathrm{C}$. The TSL is attributed to

the ${ }^{3} \mathrm{~T}_{1 \mathrm{u}} \rightarrow{ }^{1} \mathrm{~A}_{1 \mathrm{~g}}$ transition of $\mathrm{Sb}^{3+}$ according to the TSL spectra. In addition, the dose response curves for all the glow peaks have good linearity.

\section{References}

1 T. Yanagida, A. Yoshikawa, Y. Yokota, K. Kamada, Y. Usuki, S. Yamamoto, M. Miyake, M. Baba, K. Sasaki, and M. Ito: IEEE Trans. Nucl. Sci. 57 (2010) 1492.

2 C. L. Melcher: Nucl. Instrum. Methods Phys. Res., Sect. B 40-41 (1989) 1214.

3 D. Totsuka, T. Yanagida, K. Fukuda, N. Kawaguchi, Y. Fujimoto, Y. Yokota, and A. Yoshikawa: Nucl. Instrum. Methods Phys. Res., Sect. A 659 (2011) 399.

4 I. Holl, E. Lorenz, and G. Mageras: IEEE Trans. Nucl. Sci. 35 (1988) 105.

5 L. A. Kappers, R. H. Bartram, D. S. Hamilton, C. Brecher, A. Lempicki, V. Gaysinskiy, E. E. Ovechkina, and V. V. Nagarkar: Radiat. Meas. 42 (2007) 537.

6 P. Schotanus, R. Kamermans, and P. Dorenbos: IEEE Trans. Nucl. Sci. 37 (1990) 177.

7 S. C. Thacker, B. Singh, V. Gaysinskiy, E. E. Ovechkina, S. R. Miller, C. Brecher, and V. V. Nagarkar: Nucl. Instrum. Methods Phys. Res., Sect. A 604 (2009) 89.

8 V. V. Nagarkar, C. Brecher, E. E. Ovechkina, V. Gaysinskiy, S. R. Miller, S. Thacker, A. Lempicki, and R. H. Bartram: IEEE Trans. Nucl. Sci. 55 (2008) 1270.

9 Y. Wu, G. Ren, M. Nik1, X. Chen, D. Ding, H. Li, S. Pan, and F. Yang: CrystEngComm. 16 (2014) 3312.

10 D. Tostuka, T. Yanagida, Y. Fujimoto, Y. Yokota, F. Moretti, A. Vedda, and A. Yoshikawa: Appl. Phys. Express 5 (2012) 052601.

11 S. Seigel and E. Gerbert: Acta Crystallogr. 17 (1964) 790.

12 D. Talapatra, B. Ghosh, and R. K. Mukherjee: Il Nuovo Cimento 13 (1991) 859.

13 K. O. Choi, S. W. Lee, H. K. Bae, S. H. Jung, C. K. Chang, and J. G. Kang: J. Chem. Phys. 94 (1991) 6420.

14 Y. Toyotomi and R. Onaka: J. Phys. Soc. Jpn. 46 (1979) 1861.

15 A. Fukuda: Phys. Rev. B 1 (1970) 4161.

16 E. W. J. L. Oomen, W. M. A. Smit, and G. Blasse: J. Phys. C: Solid State Phys. 19 (1986) 3263.

17 Z. L. Wang, G. S. Zheng, S. Q. Wang, Q. S. Qin, H. L. Zhou, and J. C. Zhang: Acta Phys. Chim. Sin. 61 (2012) 147805.

18 T. Yanagida, K. Kamada, Y. Fujimoto, H. Yagi, and T. Yanagitani: Opt. Mater. 35 (2013) 2480.

19 T. Yanagida, Y. Fujimoto, K. Fukuda, and V. Chani: Nucl. Instrum. Methods A 729 (2013) 58.

20 T. Yanagida, Y. Fujimoto, T. Ito, K. Uchiyama, and K. Mori: Appl. Phys. Express 7 (2014) 062401.

21 S. Kubota, J. Ruan, M. Itoh, S. Hashimoto, and S. Sakuragi: Nucl. Instrum. Methods Phys. Res. A 289 (1990) 253.

22 T. Tsuboi, P. Ahmet, and J. G. Kang: J. Phys.: Condens. Matter 4 (1992) 531.

23 P. W. M. Jacobs: J. Phys. Chem. Solids 52 (1991) 35.

24 J. G. Kang, F. Cusso, T. F. Belliveau, and D. J. Simkin: J. Phys. Chem. C 18 (1985) 4753.

25 B. Gaveau, E. Mihokova, M. Nikl, K. Polak, and L. S. Schulman: Phys. Rev. B 58 (1998) 6938.

26 A. A. Braner and A. Halperin: Phys. Rev. B 4 (1971) 543. 
27 T. Tsuboi, Y. Nakai, K. Oyama, and P. W. M. Jacobs: Phys. Rev. B 8 (1973) 1698.

28 P. W. M. Jacobs, Y. Kamishina, L. L. Coatsworth, and M. J. Stillman: J. Lumin. 18\&19 (1979) 619.

29 A. Fukuda: J. Phys. Soc. Jpn. 27 (1969) 96.

30 Y. Toyozawa and M. Inoue: J. Phys. Soc. Jpn. 20 (1965) 1289.

31 E. W. J. L. Oomen and G. J. Dirksen: Mater. Res. Bull. 20 (1985) 453.

32 V. Nagirnyi, S. Zazubovich, and N. Jaanson: Phys. Status Solidi B 175 (1993) 155.

33 E. Mihokova, V. Nagirny, M. Nikl, A. Stolovich, G. P. Pazzi, S. Zazubovich, and V. Zepelin: J. Phys.: Condens, Matter. 8 (1996) 4301.

34 V. Nagirnyi, M. Nikl, G. P. Pazzi, and S. Zazubovich: Chem. Phys. Lett. 268 (1997) 280.

35 S. Zazubovich, A. Voloshinovskii, and G. Stryganyuk: Phys. Status Solidi B 233 (2002) 238.

36 V. Nagirnyi, S. Zazubovich, V. Zepelin, M. Nikl, and G. P. Pazzi: Chem. Phys. Lett. 227 (1994) 533.

37 S. W. S. Mckeever: Thermoluminescence of Solids (Cambridge University Press, New York, 1985).

38 R. Chen: J. Phys. D: Appl. Phys. 16 (1983) L107. 